\title{
PENGARUH GAYA KEPEMIMPINAN, MORALITAS INDIVIDU, DAN AUDIT INTERNAL TERHADAP RISIKO FRAUD
}

\author{
Noviani, Putri Nurmala, Akhmad Sigit Adiwibowo \\ Program Studi Akuntansi, Fakultas Ekonomi, Universitas Pamulang \\ novianisatu@gmail.com,pnurmala@gmail.com,akhmad.s.adiwibowo@gmail.com
}

\begin{abstract}
This study aims to determine the effect of leadership style, individual morality and internal audit on the risk of fraud. This type of research uses a quantitative approach. Sampling using purposive sampling technique. The data collection instrument used a questionnaire. The number of respondents was 110 managers and staff of the procurement section of PT Robina Putra Perkasa. Data were analyzed using multiple linear regression. The results showed that (1) the leadership style at PT Robina Putra Perkasa was dominated by a democratic style. Democratic leadership style directly negatively affects the risk of fraud; (2) individual morality level of PT Robina Putra Perkasa is post-conventional. The level of individual morality has a negative effect on the risk of fraud; (3) internal audit at PT Robina Putra Perkasa is categorized as very good. Internal audit also has a negative effect on fraud risk; (4) simultaneously, leadership style, individual morality and internal audit affect the risk of fraud.
\end{abstract}

Keywords: leadership style, individual morality, internal audit, fraud risk

\begin{abstract}
ABSTRAK
Penelitian ini bertujuan untuk mengetahui pengaruh antara gaya kepemimpinan, moralitas individu dan audit internal terhadap risiko fraud. Jenis penelitian menggunakan pendekatan kuantitatif. Pengambilan sampel menggunakan teknik purposive sampling. Instrumen pengambilan data menggunakan kuesioner. Jumlah responden sebanyak 110 manajer dan staff bagian pengadaan barang PT Robina Putra Perkasa. Data dianalisis menggunakan regresi linier berganda. Hasil penelitian menunjukkan bahwa (1) gaya kepemimpinan di PT Robina Putra Perkasa didominasi oleh gaya demokratis. Gaya kepemimpinan demokratis secara langsung berpengaruh negatif terhadap risiko fraud; (2) level moralitas individu PT Robina Putra Perkasa adalah post-conventional. Level moralitas individu berpengaruh negatif terhadap risiko fraud; (3) audit internal di PT Robina Putra Perkasa tergolong kategori sangat baik. Audit internal juga berpengaruh negatif terhadap risiko fraud; (4) secara simultan, gaya kepemimpinan, moralitas individu dan audit internal berpengaruh terhadap risiko fraud.
\end{abstract}

Kata Kunci: gaya kepemimpinan, moralitas individu, audit internal, risiko fraud 


\section{PENDAHULUAN}

Perkembangan dunia akuntansi yang semakin pesat saat ini tidak hanya membawa manfaat bagi masyarakat tetapi juga menjadi sumber masalah kecurangan (fraud) yang sangat kompleks seperti misalnya korupsi, penyalahgunaan aset dan manipulasi laporan keuangan. Dewasa ini, perkembangan praktik kecurangan tidak hanya terjadi pada sektor pemerintahan tetapi juga banyak terjadi pada sektor swasta.

Fraud merupakan perbuatan yang dilakukan oleh orang yang berada di dalam organisasi untuk mengambil keuntungan untuk dirinya sendiri atau sekelompok orang. Hal ini senada dengan yang diungkapkan oleh Hiro (2006) yang mendefinisikan fraud sebagai suatu susunan ketidakberesan dan perbuatan ilegal yang merupakan suatu muslihat yang dilakukan untuk keuntungan atau kerugian organisasi, yang dilakukan oleh orang di luar atau orang di dalam organisasi.

Menurut The Association Certified Fraud Examiners (2012), fraud dikelompokkan menjadi 3 macam yaitu fraud laporan keuangan (fraudulent financial reporting), penyalahgunaan asset (fraud assets misappropriation), dan korupsi (corruption). Fraudulent financial reporting merupakan fraud yang dilakukan oleh manajemen atau pengelola perusahaan dalam bentuk salah saji material atas laporan keuangan yang merugikan stakeholder khususnya investor, kreditor atau otoritas perpajakan.

Fraud assets misappropriation merupakan fraud yang terbagi dalam fraud kas dan fraud non kas. Sedangkan korupsi merupakan fraud yang dapat dibedakan ke dalam pertentangan kepentingan (conflict of interest), suap (bribery), pemberian ilegal (illegal gratuity), dan pemerasan (economic extortion).

Tindakan fraud pernah terjadi di PT Robina Putra Perkasa Group pada tahun 2015. Terdapat kasus fraud dalam pengadaan barang mesin jet pump senilai 110 juta rupiah. Kasus ini terjadi di salah satu hotel di Makassar yang dilakukan oleh bagian purchasing. Kasus penggelapan uang setoran (remittance) hasil penjualan yang dilakukan oleh kasir dengan modus tidak menyetorkan uang tunai hasil penjualan tersebut secara rutin yang berakibat menumpuknya uang tunai di tangan kasir sehingga menimbulkan peluang untuk memakai uang tersebut, kemudian di tahun yang sama terjadi kasus manipulasi voucher dan harga kamar yang dilakukan oleh front officer, dan juga kasus kecurangan akuntansi serta penggelapan uang yang dilakukan oleh bagian income audit senilai hampir 400 juta rupiah pada tahun 2014. Berdasarkan uraian tersebut diatas, gaya kepemimpinan, level moralitas individu, dan audit internal organisasi merupakan faktor yang akan diteliti sebagai penyebab terjadinya kecurangan (fraud) di enam hotel milik PT Robina Putra Perkasa (Group). 


\section{TINJAUAN LITERATUR}

Teori utama yang melandasi penelitian ini adalah teori agensi (agency theory). Teori agensi merupakan dasar yang digunakan perusahaan untuk memahami konsep corporate governance. Jensen dan Meckling (1976) menyatakan bahwa teori agensi dapat menjelaskan hubungan yang terjadi antara pemilik dan pemegang saham (principal) dengan manajemen (agent). Hubungan keagenan yang terjadi merupakan sebuah kontrak antara satu orang atau lebih (principal) yang mempekerjakan orang lain (agent) untuk memberikan suatu jasa dan kemudian mendelegasikan wewenang pengambilan keputusan kepada agen tersebut.

Teori lainnya yang mendukung penelitian ini adalah fraud triangle theory yang diungkapkan oleh Cessey (1953), dan GONE theory oleh Bologna (1953). Dalam teori segitiga kecurangan (fraud triangle theory) dijelaskan tiga hal yang mendorong seseorang untuk melakukan kecurangan (fraud) yaitu incentive/pressure (tekanan), opportunity (peluang), dan attitude (rasionalisasi). Bologna (1993) menjelaskan fraud dengan GONE theory yang terdiri dari 4 (empat) faktor yang mendorong seseorang berperilaku menyimpang yaitu: greed (keserakahan), opportunity (kesempatan), need (kebutuhan) dan exposure (pengungkapan).

Berdasarkan teori yang dikemukakan diatas maka peneliti membuat rerangka teoritis seperti di Gambar 1. berikut ini.

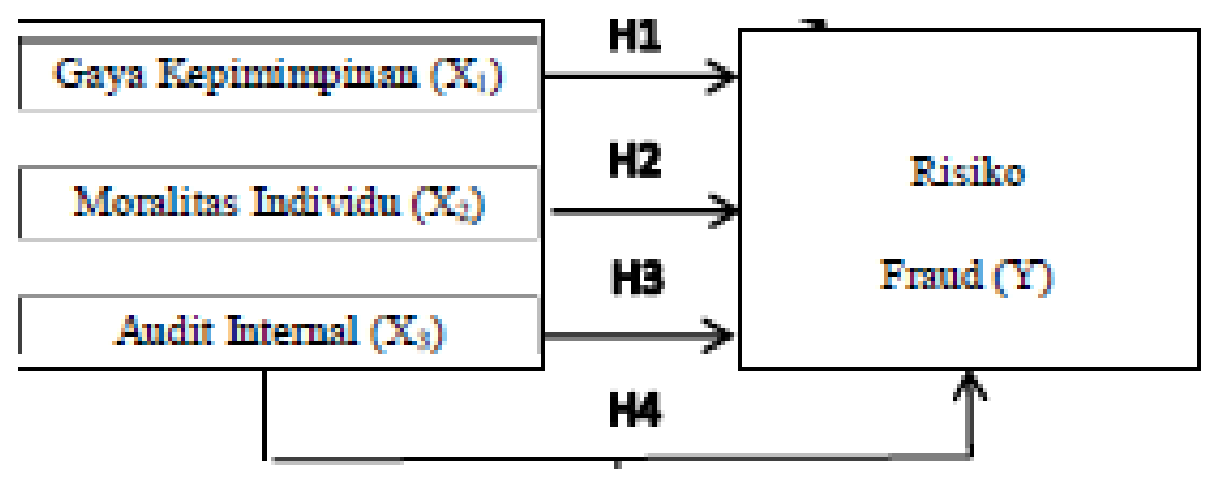

Gambar 1. Rerangka Teoritis

\section{Pengaruh gaya kepemimpinan terhadap risiko fraud}

Perilaku karyawan terbentuk dari cara pemimpin dalam mencapai sasaran organisasi dan memberikan motivasi (Subramanian, 2008). Karyawan cenderung mengikuti peraturan perusahaan ketika dipimpin dengan menerapkan gaya kepemimpinan yang tepat (Pramudita, 2013). Gaya kepemimpinan yang tepat adalah gaya kepemimpinan yang dapat memberikan motivasi kerja pada bawahannya. Motivasi dapat dilakukan dengan memberikan reward, pujian, promosi jabatan serta pendelegasian tugas yang jelas (Nurjanah, 2008). Sehingga 
dapat dikatakan bahwa gaya kepemimpinan yang tepat akan berpengaruh terhadap risiko fraud.

Semakin tepat gaya kepemimpinan yang digunakan oleh seorang pemimpin akan menurunkan risiko fraud. Pada penelitian terdahulu yang menyelidiki dampak gaya kepemimpinan terhadap risiko fraud seperti yang dikemukakan oleh Pramudita (2013), bahwa gaya kepemimpinan berpengaruh negatif terhadap risiko fraud. Hal ini berarti bahwa gaya kepemimpinan yang tepat di suatu organisasi dapat memberikan motivasi kerja sehingga menurunkan risiko fraud. Lebih lanjut, Zulkarnain, (2013) dan (Faisal, 2013) berpendapat bahwa terdapat pengaruh negatif antara gaya kepemimpinan terhadap risiko fraud. Sudibyo (2016) berpendapat bahwa gaya kepemimpinan demokratis berpengaruh negatif terhadap risiko fraud. Dengan demikian peneliti merumuskan hipotesis pertama sebagai berikut:

$\mathbf{H}_{1}$ : Gaya kepemimpinan berpengaruh negatif terhadap risiko fraud.

\section{Pengaruh moralitas individu terhadap risiko fraud}

Menurut Moroney dan McDevitt (2008) individu dengan level penalaran moral tinggi dalam perbuatannya akan lebih berorientasi pada prinsip-prinsip moral yang universal. Puspasari (2012) menemukan adanya interaksi antara moralitas individu pengendalian internal dalam mempengaruhi kecenderungan kecurangan akuntansi. Interaksi yang dimaksud adalah perubahan pada satu level faktor level moral atau pada kondisi pengendalian internal, akan menyebabkan perubahan individu dalam melakukan kecurangan akuntansi. Individu dengan level penalaran moral rendah cenderung akan memanfaatkan kondisi tidak terdapat elemen pengendalian internal dalam organisasi tersebut untuk kepentingan pribadinya (self-interest), misalnya tindakan yang berhubungan dengan kecurangan akuntansi. Kondisi tersebut sesuai dengan yang ada dalam tingkatan level pre-conventional Kohlberg yaitu individu yang memiliki level penalaran moral rendah memiliki motivasi $u$ tama untuk kepentingan pribadinya. Sementara itu, individu dengan level penalaran tinggi dalam kondisi tidak terdapat elemen pengendalian internal di organisasi tetap tidak akan melakukan kecurangan akuntansi yang tidak etis dan akan merugikan banyak pihak.

Kohlberg menyatakan bahwa taat kepada peraturan yang ada karena menghindari sanksi tertentu termasuk dalam tahap yang rendah yaitu level pre-conventional. Individu dengan penalaran moral rendah dalam kondisi terdapat elemen pengendalian internal cenderung tidak akan melakukan kecurangan akuntansi karena takut perbuatannya akan terdeteksi oleh pengendalian internal organisasi dan ia akan mendapat sanksi hukum. 
Terdapat bukti empiris dari Moroney dan McDevitt (2008) yang menemukan bahwa individu dengan level penalaran moral rendah lebih berorientasi pada peraturan dan sanksi hukum yang mungkin didapatkan. Hertanto (2015) menyatakan bahwa moralitas individu berpengaruh negatif terhadap kecurangan akuntansi. Berdasarkan hal tersebut, maka hipotesis yang diajukan dalam penelitian ini adalah:

$\mathbf{H}_{2}$ : Moralitas individu berpengaruh negatif terhadap risiko fraud

\section{Pengaruh audit internal terhadap risiko fraud}

Herawati (2013) menyatakan bahwa terdapat pengaruh yang cukup signifikan antara profesionalisme auditor internal terhadap pendeteksian fraud assets misappropriation. Hal serupa dikemukakan oleh Pratiwi (2015) dalam penelitiannya menunjukkan bahwa frofesionalisme seorang auditor internal terbukti memberikan pengaruh terhadap pendeteksian Fraud Asset Misappropriation. Semakin tinggi sikap profesionalisme seorang auditor internal dalam menjalankan tanggung jawabnya akan meningkatkan pendeteksian fraud assets misappropriation. Berdasarkan hal tersebut maka penulis merumuskan hipotesis ketiga adalah:

H3: Audit intern berpengaruh negatif terhadap risiko fraud

Berdasarkan uraian diatas, penulis merumuskan hipotesis ke-empat adalah:

H4: Gaya kepemimpinan, moralitas individu, dan audit internal secara simultan berpengaruh terhadap risiko fraud.

\section{METODE PENELITIAN}

Penelitian ini dilakukan di enam hotel milik PT Robina Putra Perkasa, dimulai dari tanggal 02 Januari sampai dengan 02 Maret 2017. Penelitian menggunakan metode asosiatif. Menurut Sugiyono (2010) menjelaskan bahwa penelitian asosiatif adalah penelitian yang digunakan untuk mengetahui hubungan antara dua variabel atau lebih. Penelitian ini bertujuan untuk memperoleh gambaran mengenai pengaruh gaya kepemimpinan, moralitas individu dan audit internal terhadap risiko fraud assets misappropriation .

Populasi dalam penelitian ini berjumlah 110 orang yang terdiri dari seluruh karyawan bagian purchasing, accounting, human resource, dan front office, serta seluruh manager dan auditor internal pada hotel - hotel milik PT Robina Putra Perkasa.

Sampel penelitian ditentukan menggunakan purposive sampling. Menurut Sugiyono (2011), Metode purposive sampling adalah suatu metode pengambilan sampel yang 
disesuaikan dengan kriteria-kriteria tertentu. Pemilihan sampel menggunakan metode purposive sampling berdasarkan beberapa kriteria, diantaranya adalah usia responden minimal 20 tahun, tingkat pendidikan minimal Diploma 3 (D3), dan pengalaman kerja minimal 1 tahun. Responden diambil dari manajer dan staf pada bagian accounting, purchasing, human resource dan front office, serta auditor internal. Divisi responden merupakan divisi yang paling rentan dan berpotensi terjadi risiko fraud asset missapropriation.

Data yang digunakan dalam penelitian ini bersumber dari data primer. Data primer merupakan data yang langsung diberikan kepada pengumpul data (Sugiyono, 2011). Adapun instrumen pengumpulan data primer menggunakan kuesioner. Kuesioner merupakan teknik pengumpulan data yang dilakukan dengan cara memberi seperangkat pertanyaan atau peryataan tertulis kepada responden untuk dijawabnya (Sugiyono, 2011). Skala likert digunakan dalam penyusunan kuesioner penelitian ini. Data primer diperoleh dengan menggunakan pernyataan yang telah terstruktur dengan tujuan untuk mengumpulkan informasi dari manajer dan staf bagian accounting, purchasing, dan front office di PT Robina Putra Perkasa.

Analisis data merupakan suatu proses penyederhanaan data ke dalam bentuk yang lebih mudah dibaca dan diinterprestasikan. Dengan menggunakan metode kuantitatif diharapkan akan didapatkan hasil pengukuran yang lebih akurat tentang respon yang diberikan responden, sehingga data yang berbentuk angka tersebut dapat diolah dengan menggunakan metode statistik pada penelitian ini, penulis menggunakan program statistik SPSS 22 dalam menganalisis data yang didapat untuk pengolahannya.

Statistik deskriptif adalah statistik yang digunakan untuk menganalisis data dengan cara mendeskripsikan atau menggambarkan data yang telah terkumpul sebagaimana adanya tanpa bermaksud membuat kesimpulan yang berlaku untuk umum atau generalisasi, (Sugiyono, 2011). Menurut Ghozali (2005) dalam Latifa Agustin (2010), mengatakan bahwa statistik deskriptif memberikan gambaran atau deskripsi suatu data yang dilihat dari nilai rata-rata (mean), standar deviasi, varian, maksimum, minimum, sum, range, kurtosis dan skewness (kemencengan distribusi). Uji kualitas data dilakukan untuk menguji validitas dan reliabilitas data yang diperoleh melalui instrument kuesioner.

Uji validitas digunakan untuk mengukur valid atau tidaknya suatu instrumen dalam kuesioner. Instrumen yang valid berarti instrumen tersebut dapat digunakan untuk mengukur apa yang seharusnya diukur (Sugiyono, 2011). Istilah valid atau validitas berasal dari kata 
validity yang mempunyai arti sejauh mana ketepatan dan kecermatan alat ukur dalam melakukan fungsi ukurnya (Yamin dan Kurniawan, 2009).

Untuk melihat validitas setiap pertanyaan dari setiap variabelnya dapat dilihat pada kolom Corrected Items-Correlation. Di mana, nilai yang dihasilkan sebenarnya merupakan hasil korelasi antara tiap butir pertanyaan dengan totalnya yang dilakukan koreksi variansnya, (Sofyan Yamin dan Heri Kurniawan dalam buku SPSS Complete, 2009:284). Jika nilai rhitung lebih besar daripada r-tabel maka pertanyaan tersebut dikatakan valid sedangkan jika r-hitung lebih kecil daripada r-tabel, maka pertanyaan tersebut dikatakan tidak valid. Nilai rhitung dapat dilihat pada kolom Corrected Items-Correlation.

Reliabilitas merupakan serangkaian indikator gagasan laten yang konsisten dalam pengukurannya. Kriteria reliabilitas menggunakan nilai Cronbach's Alpha sebagai berikut: (1) jika alpha > 0,90 maka reliabilitas sempurna; (2) jika alpha antara 0,70-0,90 maka reliabilitas tinggi; (3) jika alpha antara 0,50-0,70 maka reliabilitas moderat; dan (4) jika alpha $<0,50$ maka reliabilitas rendah.

Dalam penelitian ini terdapat empat variabel, yaitu gaya kepemimpinan, moralitas individu dan audit internal sebagai variabel independen dan risiko fraud sebagai variabel dependen. Metode analisis yang digunakan adalah metode regresi linier berganda. Koefisien Determinasi $\left(\mathrm{R}^{2}\right)$ bertujuan untuk mengetahui seberapa besar kemampuan variabel independen menjelaskan variabel dependen. Nilai koefisien determinasi adalah antara nol sampai satu. Hal ini berarti jika nilai $\mathrm{R}^{2}=0$, maka tidak adanya pengaruh antara variabel independen terhadap variabel dependen. Jika $\mathrm{R}^{2}$ mendekati satu, menunjukkan bahwa semakin besar pengaruh variabel indepeden terhadap variabel dependen.

\section{HASIL PENELITIAN DAN PEMBAHASAN}

Analisis regresi linier berganda menghendaki model yang bebas dari uji asumsi klasik, yaitu uji normalitas, heteroskedastisitas, dan multikoliniersitas. Uji normalitas dapat dideteksi dengan melihat penyebaran data (titik) pada sumbu diagonal dari grafik. Berdasarkan hasil uji normalitas, data (titik) menyebar disekitar garis diagonal dan mengikuti arah garis diagonal maka menunjukkan pola distribusi normal yang mengindikasikan bahwa model regresi memenuhi asumsi normalitas. (Ghozali, 2011).

Selanjutnya uji multikolinieritas yang digunakan untuk mengetahui apakah ada hubungan atau korelasi diantara variabel independen. Hasil uji multikolinieritas disajikan pada Tabel 1. 
Tabel 1. Hasil uji multikolinieritas

\begin{tabular}{lcc}
\hline \multicolumn{1}{c}{ Variabel } & Tolerance & VIF \\
\hline Gaya kepeimpinan & 0,268 & 3,734 \\
Moralitas individu & 0,395 & 2,529 \\
Audit intern & 0,420 & 2,381 \\
\hline
\end{tabular}

Pada tabel 1, terlihat nilai tolerance untuk gaya kepemimpinan, moralias individu dan audit internal memiliki nilai tolerance $>0,1$ dan nilai $\mathrm{VIF}<10$. Berdasarkan hasil tersebut, dapat dikatakan bahwa tidak terjadi korelasi diantara variabel gaya kepemimpinan, moralitas individu dan audit internal atau tidak terjadi multikolinearitas dalam model regresi ini.

Uji heteroskedastisitas bertujuan untuk menguji apakah dalam suatu model regresi terdapat persamaan atau perbedaan varian. Pada penelitian ini, uji heteroskedastisitas menggunakan uji glejser. Uji glejser dilakukan dengan cara meregresikan antara variabel independen dengan nilai absolut residualnya. Dasar pengambilan keputusan, jika nilai signifikasnsi antara variabel independen dengan absolut residual lebh dari 0,05 maka tidak terjadi masalah heteroskedastisitas. Hasil uji heteroskedastisitas disajikan pada Tabel 2.

Tabel 2. Hasil uji heteroskedastisitas

\begin{tabular}{lccc}
\hline \multicolumn{1}{c}{ Variabel } & Koefisien & t-statistik & Sig. \\
\hline Gaya kepemimpinan & 0,163 & 0,259 & 0,797 \\
Moralitas individu & 0,087 & 0,301 & 0,764 \\
Audit intern & $-0,223$ & $-2,904$ & 0,005 \\
\hline
\end{tabular}

Berdasarkan Tabel 2 menunjukkan signifikansi variabel gaya kepemimpinan dan moralitas individu diperoleh sebesar 0,797 dan 0,764 (lebih besar dari 0,05). Nilai signifikansi variabel audit intern diperoleh sebesar 0,05 yaitu sama dengan standar signifikansi. Hal ini berarti tidak terjadi heteroskedastisitas.

Koefisien determinasi $\left(\mathrm{R}^{2}\right)$ menyatakan persentase total variasi dari variabel dependen yang dapat dijelaskan oleh variabel independen dalam model. Nilai $\mathrm{R}^{2}$ berkisar antara 0 sampai 1. Hasil analisis $\mathrm{R}^{2}$ disajikan pada Tabel 3.

Tabel 3. Hasil uji koefisien determinasi

\begin{tabular}{lc}
\hline \multicolumn{1}{c}{ Uji } & Nilai \\
\hline $\mathrm{R}$ & 0,885 \\
R Square & 0,784 \\
Adj. R Square & 0,772 \\
error of the estimated & 0,332 \\
\hline
\end{tabular}

Berdasarkan Tabel 3 menunjukkan hasil analisis Adjusted Rsquare maka diperoleh angka $\mathrm{R}$ sebesar 0,885, hal ini menunjukkan bahwa gaya kepemimpinan, moralitas individu dan audit internal memiliki hubungan yang signifikan dengan risiko fraud, sebab nilai $\mathrm{R}$ positif dan mendekati 1. Kemudian nilai Adjusted Rsquare sebesar 0,772 (77,2\%), hal ini menunjukkan 
bahwa persentase pengaruh variabel independen (kepemimpinan, moralitas individu dan audit internal) mampu menjelaskan sebesar 77,2\% variasi dari pencegahan tindakan kecurangan.

Kemudian standar error of the estimated adalah suatu ukuran banyaknya kesalahan model regresi dalam memprediksikan risiko fraud (Y). Dari hasil analisis regresi maka diperoleh nilai standar error of the estimated sebesar 0,332. Hal ini menunjukkan bahwa banyaknya kesalahan dalam memprediksi pencegahan tindakan kecurangan dapat ditentukan sebesar 0,332 .

Analisis regresi bermaksud menguji hubungan fungsional yang terjadi antara satu variabel dependen dengan satu atau lebih variabel independen. Hal ini dimaksudkan agar dapat diketahui nilai estimasi variabel dependen yang dihasilkan atas pengaruh variabel independen. Hubungan antara variabel independen dengan variabel dependen disajikan pada Tabel 4.

Tabel 4. Hasil analisis regresi berganda

\begin{tabular}{lccc}
\hline \multicolumn{1}{c}{ Variabel } & Koefisien & t-statistik & Sig. \\
\hline Konstanta & $-0,735$ & $-2,0229$ & 0,012 \\
Gaya kepemimpinan & $-1,235$ & 1,222 & 0,014 \\
Moralitas individu & $-0,359$ & $-1,197$ & 0,030 \\
Audit intern & $-1,100$ & 8,791 & 0,000 \\
\hline
\end{tabular}

Berdasarkan Tabel 4, diperoleh persamaan regresi sebagai berikut:

$$
Y=-0,735-1,235 X_{1}-0,359 X_{2}-1,100 X_{3}
$$

Konstanta sebesar -0,735 menyatakan bahwa jika tidak ada gaya kepemimpinan, moralitas individu, dan audit internal, maka besarnya risiko fraud adalah -0,735. Koefisien regresi -1,235 meyatakan bahwa setiap penambahan satu kesatuan gaya kepemimpinan, maka akan mengurangi risiko fraud sebesar 1,235, jika variabel yang lain tetap. Koefisien regresi sebesar -0,359 menyatakan bahwa setiap kenaikan satu kesatuan moralitas individu, maka akan mengurangi risiko fraud sebesar 0,359, jika variabel yang lain tetap. Koefisien regresi 1,100 menyatkan bahwa setiap kenaikan satu kesatuan audit internal, maka akan mengurangi risiko fraud sebesar 1,100, jika variabel yang lain tetap.

Untuk menguji sejauh mana pengaruh masing-masing variabel yakni pengaruh gaya kepemimpinan, moralitas individu dan audit internal terhadap risiko fraud maka digunakan uji signifikan, yakni dengan membandingkan thitung dan $t_{\text {tabel }}$ dari masing-masing variabel. Hasil uji t untuk variabel $\mathrm{X}_{1}$ (gaya kepemimpinan) diperoleh nilai thitung 1,891 dengan tingkat signifikansi 0,014. Dengan menggunakan batas signifikansi 0,05 didapat $t_{\text {tabel }}$ sebesar 1,67252 
ini berarti $t_{\text {hitung }}>\mathrm{t}_{\text {tabel }}$ serta memiliki nilai probabilitas yang lebih kecil dari nilai standar sig sebesar $0,014<0,05$, dan diperoleh nilai koefisien (unstandardized coefficients) sebesar 1,235, maka dapat dikatakan bahwa gaya kepemimpinan secara parsial mempunyai pengaruh negatif yang signifikan terhadap risiko fraud, maka $\mathrm{H}_{1}$ diterima.

Hasil uji t untuk variabel $\mathrm{X}_{2}$ (moralitas individu) diperoleh nilai thitung 3,992 dengan tingkat signifikansi 0,030. Dengan menggunakan batas signifikansi 0,05 didapat $t_{\text {tabel }}$ sebesar 1,67252 ini berarti $t_{\text {hitung }}>t_{\text {tabel }}$ serta memiliki nilai probabilitas yang lebih kecil dari nilai standar sig sebesar $0,030<0,05$, dan diperoleh nilai koefisien (unstandardized coefficients) sebesar -0,359, maka dapat dikatakan bahwa moralitas individu secara parsial mempunyai pengaruh negatif yang signifikan terhadap risiko fraud, maka $\mathrm{H}_{2}$ diterima.

Hasil uji t untuk variabel $\mathrm{X}_{3}$ (audit internal) diperoleh nilai thitung 8.791 dengan tingkat signifikansi 0,000. Dengan menggunakan batas signifikansi 0,05 didapat tabel sebesar 1,67252 ini berarti $t_{\text {hitung }}>t_{\text {tabel }}$ dan memiliki nilai probabilitas yang lebih kecil dari nilai standar sig sebesar $0,000<0,05$ serta diperoleh nilai koefisien sebesar -1,100 maka dapat dikatakan bahwa audit internal secara parsial mempunyai pengaruh negatif yang signifikan terhadap risiko fraud, maka $\mathrm{H}_{3}$ diterima.

Uji F digunakan untuk mengetahui signifikansi dari model regresi yang digunakan. Cara yang digunakan adalah dengan membanding-kan $F_{\text {hitung dengan }} F_{\text {tabel }}$ pada taraf signifikansi $(0,05)=5 \%$. Hasil uji $\mathrm{F}$ diperoleh $\mathrm{F}_{\text {hitung }}=67,755$ sedangkan $\mathrm{F}_{\text {tabel }}$ pada taraf signifikansi $5 \%$ adalah sebesar 2,77. Dikarenakan $F_{\text {hitung }}>F_{\text {tabel }}(67,77>2,77)$, dan nilai sig lebih kecil dari 0,05 $(0,00<0,05)$ maka model regresi yang digunakan adalah berpengaruh signifikan. Ini berarti bahwa terdapat pengaruh signifikan secara bersama-sama (simultan) antara gaya kepemimpinan, moralitas individu dan audit internal terhadap risiko fraud, maka $\mathrm{H}_{4}$ diterima.

\section{Gaya kepemimpinan berpengaruh negatif terhadap risiko fraud}

Berdasarkan hasil penelitian menunjukkan bahwa gaya kepemimpinan yang diterapkan oleh PT Robina Putra Perkasa, yaitu gaya kepemimpinan demokratis berpengaruh negatif signifikan terhadap risiko fraud. Hal ini karena nilai $t_{\text {statistic }} 1,891>1,673$ dan nilai sig $0,014<0,05$, serta nilai koefisien diperoleh sebesar $-1,235$.

Selain itu, dari sembilan indikator risiko fraud di PT Robina Putra Perkasa masuk kategori kecil. Artinya PT Robina Putra Perkasa memiliki kebijakan mengenai penerimaan hadiah, diskon, jasa dan sejenisnya, kebijakan mengenai proses tender atau penawaran pembelian, review terhadap proses pembelian, review terhadap syarat-syarat penawaran tender, dokumen-dokumen tender, komunikasi antara peserta dengan panitia tender, 
kerahasiaan informasi dokumen penawaran, kerahasiaan informasi dokumen penawaran, review terhadap kualifikasi peserta tender dan aturan pemenang tender yang telah diatur dengan baik dan dalam pelaksanaanya sudah berjalan cukup baik, sehingga risiko fraud pada perusahaan ini kecil. Kedua variabel tersebut menunjukkan hasil ada pengaruh negatif. Gaya kepemimpinan demokratis berpengaruh negatif terhadap risiko fraud.

Hasil penelitian ini sejalan dengan Sudibyo (2016), Pramudita (2013); Zulkarnain (2013) dan Faisal (2013) yaitu gaya kepemimpinan berpengaruh negatif terhadap risiko fraud. Dalam penelitian tersebut, keberhasilan penerapan gaya kepemimpinan dikarenakan adanya hubungan yang baik antara atasan dengan bawahan, dimana pemimpin telah menyampaikan pembagian tugas dengan baik. Hal ini berarti pemimpin menguasai pembagian struktur tugas dan tanggung jawab masing-masing pegawai dan pemimpin memiliki posisi kekuatan, serta proses komunikasi berjalan dengan baik dalam suatu instansi, sehingga proses penyampaian informasi dari atasan ke bawahan berjalan baik, sehingga arah dan tujuan organisasi dapat tercapai. Suatu tekanan (pressure) akan membuat pegawai cenderung melakukan tindak fraud, baik faktor keuangan dari individu maupun non keuangan yang berkaitan dengan faktor tekanan dari pekerjaan itu sendiri yaitu dari gaya kepemimpinan seorang atasan. Tekanan dari pemimpin akan membuat seorang pegawai akan bertindak tidak sesuai dengan keinginan atasan. Fenomena tersebut memicu terjadinya tindak fraud dalam suatu instansi.

Gaya kepemimpinan demokratis berpengaruh terhadap perilaku karyawan. Karyawan di PT Robina Putra Perkasa mendapatkan motivasi berupa reward yang didapatkan setiap bulan dan besarannya tergantung pada omset hotel (service charge), pujian, promosi jabatan serta pendelegasian tugas yang jelas, sehingga karyawan merasa kinerjanya dihargai, dihormati, dan diakui keberadaannya. Hal ini membawa pengaruh negatif terhadap risiko fraud. Dengan demikian, dapat disimpulkan bahwa semakin baik gaya kepemimpinan yang diterapkan, maka akan mengurangi risiko fraud.

\section{Moralitas individu berpengaruh negatif terhadap risiko fraud}

Berdasarkan hasil penelitian menunjukkan moralitas individu di PT Robina Putra Perkasa berpengaruh negatif terhadap risiko fraud. Hal ini karena nilai nilai $\mathrm{t}_{\text {statistic }}$ 3,992>1,673 dan nilai sig 0,030<0,05, serta nilai koefisien didapat sebesar $-0,359$. Data penelitian pada moralitas individu menunjukkan hasil bahwa level moralitas individu di PT Robina Putra Perkasa tergolong memiliki level moral yang tinggi (level post-conventional). Hal ini berarti individu dengan level moral tinggi kecenderungan melakukan kecurangan akuntansi akan lebih rendah dibandingkan individu yang memiliki level moral yang rendah. 
Hasil penelitian ini membuktikan apa yang ada dalam hirarki tahap perkembangan moral Kohlberg. Semakin tinggi tahapan moralitas individu (tahapan post-conventional), semakin individu tersebut memperhatikan kepentingan yang lebih luas dan universal daripada kepentingan organisasinya semata, apalagi kepentingan individunya. Semakin tinggi level moral individu, semakin berusaha untuk menghindarkan diri dari kecenderungan melakukan kecurangan akuntansi yang akan merugikan banyak pihak. Hasil penelitian ini memperkuat temuan Dewi (2014), Liyanarachi (2009), Arnold dan Ponemon (1991), Welton (1994), Wilopo (2006), dan Puspasari (2012) bahwa individu yang memiliki level penalaran moral tinggi akan lebih senstif terhadap isu-isu etika, sehingga akan cenderung melakukan perbuatan yang etis. Dengan demikian, semakin tinggi level moralitas individu, maka akan mengurangi risiko fraud.

\section{Audit Intern berpengaruh negatif terhadap risiko fraud}

Berdasarkan hasil penelitian menunjukkan audit internal di PT Robina Putra Perkasa berpengaruh negatif signifikan terhadap risiko fraud. Hal ini karena nilai nilai $\mathrm{t}_{\text {statistic }}$ $8,791>1,673$ dan nilai sig $0,000<0,05$, serta nilai koefisien diperoleh sebesar $-1,100$. Data penelitian pada audit internal menunjukkan bahwa audit internal yang terdiri dari lima dimensi audit dengan lima belas indikator menunjukkan skor rata-rata sebesar 106, yang berarti bahwa audit internal di PT Robina Putra Perkasa termasuk ke dalam kriteria audit internal yang sangat baik. Artinya auditor memiliki indepenensi, profesionalisme, keandalan informasi, program audit serta pelaksanaan kegiatan audit yang baik sehingga audit internal dapat meningkatkan kesadaran dan pemahaman karyawan mengenai risiko fraud.

Hal ini berarti bahwa audit internal yang sangat baik akan mengurangi risiko fraud. Hipotesis ini sejalan dengan penelitian yang dilakukan oleh Wardhini (2010), Taufik (2011), Ambarwati (2013) dan Ratna (2013).

\section{Gaya kepemimpinan, moralitas individu dan audit intern secara simultan berpengaruh terhadap risiko fraud}

Berdasarkan hasil penelitian menunjukkan bahwa gaya kepemimpinan, moralitas individu, dan audit internal secara bersama-sama (simultan) berpengaruh positif terhadap risiko fraud. Hal ini karena nilai $\mathrm{F}_{\text {statistic }}(67,775>2,77)$, dan nilai sig $0,00<0,05$.

Gaya kepemimpinan demokratis yang diterapkan, level moralitas individu yang tergolong tinggi (level post-conventional) dan kriteria audit internal yang termasuk sangat baik di PT Robina Putra Perkasa membawa pengaruh yang signifikan terhadap tingkat risiko 
fraud yang tergolong kecil. Artinya, semakin baik gaya kepemimpinan, semakin tinggi level moralitas individu dan semakin baik audit internal yang dilaksanakan maka akan memperkecil risiko fraud.

\section{KESIMPULAN}

Hasil penelitian menunjukkan bahwa, gaya kepemimpinan demokratis berpengaruh negatif terhadap risiko fraud. Moralitas Individu level post conventional berpengaruh negatif terhadap risiko fraud. Audit intern dengan kriteria sangat baik berpengaruh negatif terhadap risiko fraud. Gaya kepemimpinan, moralitas individu dan audit intern secara simultan berpengaruh signifikan terhadap risiko fraud.

Dalam penelitian ini juga memiliki keterbatasan peneliti hanya menggunakan kuesioner dan observasi partisipan. Dalam penelitian ini peneliti hanya meneliti pada divisi accounting, purchasing, human resource dan front office. Penelitian selanjutnya sebaiknya menambahkan instrumen wawancara agar informasi yang digali lebih mendalam. Penelitian berikutnya sebaiknya juga meneliti pada divisi lainnya seperti house keeping dan kitchen karena kedua divisi tersebut juga termasuk divisi yang paling sering dalam hal permintaan barang sehingga kemungkinan adanya fraud juga tinggi.

\section{DAFTAR PUSTAKA}

Agustin, L. (2010). Analisis faktor- faktor yang mempengaruhi efektifitas audit internal dalam mewujudkan good corporate governance. Universitas Islam Negeri Syarif Hidayatullah Jakarta.

Alfiani, D., Nurmala, P. (2019). Pengaruh ukuran perusahaan, profitabilitas, solvabilitas, dan reputasi kantor akuntan publik terhadap audit delay. Journal of Technopreneurship on Economics and Business Review, 1(2), 79-99.

Amelia, L. (2013). Pengaruh keadilan organisasi dan sistem pengendalian intern terhadap kecurangan pada kantor cabang utama bank pemerintah di kota Padang. Universitas Padang.

Bologna, J., Robert. (1993). Handbook of Corporate Fraud. Boston: Butterworth-Heinemann.

Elqorni, A. (2009). Dokumentasi Artikel Manajemen. Retrieved Desember 20, 2016, from http://elqorni.wordpress.com

Examiners, A. C. (2012). ACFE. Retrieved Desember 1, 2016, from http://acfe.com

Faisal, M. (2013). Analisis fraud di sektor pemerintahan Kabupaten Kudus. Accounting Analysis Journal. Volume No. 1, 69-73.

Ghozali, I. (2005). Aplikasi Analisis Multivariate dengan Program SPSS, Edisi Ketiga. Semarang: Badan Penerbit Universitas Diponegoro. 
Gusnardi. (2011). Pengaruh peran pengendalian internal, audit internal, komite audit, dan pelaksanaan good corporate governance terhadap pencegahan fraud. Jurnal Ekuitas, 15.

Hadari, N., Hadari, M. (2004). Kepemimpinan yang Efektif. Yogyakarta: Gajah Mada University Press.

Hadi, S. (2004). Metodologi Research .Yogyakarta: Andi Offset.

Hendriksen, E., Van Breda, M. F. (2001). Accounting Theory (5 ${ }^{\text {ed }}$.). New York: Mc Graw-Hill.

Herawati, E. (2013). Pengaruh profesionalisme auditor internal terhadap pendeteksian fraud assets missappropriation: survey pada auditor internal BUMN yang berpusat di Kota Bandung. Repository UPI.

Hertanto, S. D. (2015). Pengaruh persepsi pegawai tentang gaya kepemimpinan, persepsi pegawai tentang sistem pengendalian internal, persepsi pegawai tentang penegakan hukum, kesesuaian kompensasi, komitmen organisasi dan moralitas individu terhadap kecenderungan kecurangan akuntansi. Repository Unika.

Hery. (2010). Potret Audit Internal. Bandung: Alfabeta.

Internal, K. O. (2004). Standar Profesional Audit Internal. Jilid 1. Jakarta: Yayasan Pendidikan Internal Audit.

Jensen, Meckling. (n.d.). Theory of the Firm: Managerial Behavior Agency Cost, and Ownership Structure. Journal of Finance Economic 3, 305-360.

Kohlberg, L. (1994). Tahap-Tahap Perkembangan Moral. Yogyakarta: Kanisius.

Kountur, R. (2007). Metode Penelitian Untuk Penulisan Skripsi dan Tesis. Edisi Revisi. Jakarta: PPM.

Kumaat, V. G. (2011). Audit Internal. Jakarta: Erlangga.

Kurniawati, D., Nurmala, P. (2020). Pengaruh tekanan eksternal, tingkat kinerja, efektifitas pengawasan audit terhadap financial statement fraud. EkoPreneur, 1(2), 257-276.

Liyanarachi, G. (2009). The impact of moral reasoning and retalitation on Whistle-Blowing: New Zealand evidence. Journal of Business Ethics 89.

Mahmuda, D., Nurmala, P. (2020). Pengaruh keahlian, pengalaman audit, dan pengetahuan akuntansi dan auditing terhadap ketepatan pemberian opini audit. Jurnal Pasar Modal dan Bisnis, 2(2). https://doi.org/10.37194/jpmb.v2i2.47

Mayangsari, S., Wilopo. (2002). Konservatisme akuntansi, value relevance dan discretionary accruals: implikasi empiris Model Feltam-Olhson (1996). Jurnal Riset Akuntansi Indonesia, 5(September), 291-310.

Moroney, J., R, E. M. (2008). The effect of moral reasoning on financial reporting decisions in a Post Sarbanes - Oxley Environment. Behavioral Research in Accounting Vol.20, 89-110.

Norbarani, L. (2012). Pendeteksian kecurangan laporan keuangan dengan analisis fraud triangle yang diadopsi dalam SAS No. 99. Prosiding Fakultas Ekonomika dan Bisnis

Universitas

Diponegoro Semarang. 
Nurjanah. (2008). Pengaruh gaya kepemimpinan dan budaya organisasi terhadap komitmen organisasi dalam meningkatkan kinerja karyawan pada Biro Lingkup Departemen Pertanian.

Diponegoro University Institutional Repository.

Nurmala, P. (2018). Factors Affecting the social responsibility disclosure practice on go public manufacturing companies. EAJ (Economics and Accounting Journal), 1(1), 64-75. http://dx.doi.org/10.32493/eaj.v1i1.y2018.p64-75

Nurmala, P., Adiwibowo, A.S. (2019). Pengaruh ukuran perusahaan, ukuran komite audit dan umur listing terhadap luas pengungkapan intellectual capital. BALANCE: Jurnal Akuntansi, Auditing dan Keuangan, 16(2). https://doi.org/10.25170/balance.v16i2.1622

Nurmala, P., Rahmawati, A.S. (2019). Pengaruh fraud pentagon terhadap deteksi kecurangan laporan keuangan. Tangible Journal, 4(2), 200-213.

Olivia, M., Nurmala, P. (2020). Pengaruh tingkat implementasi IFRS dan kualitas audit terhadap pengakuan kerugian tepat waktu. Jurnal Sosial Ekonomi dan Humaniora, 6(1), 37-43. https://doi.org/10.29303/jseh.v6i1.75

Pramudita, A. (2013). Analisis fraud di sektor pemerintahan kota Salatiga. Accounting Analysis Journal, 2(1), 35-43.

Pratiwi, R. A., Purnamasi, P., Gunawan, H. (2015). Pengaruh profesionalisme dan indepensi auditor internal terhadap pendeteksian fraud assets misappropriation pada PT Inti, PT Telkom, dan Perum Pegadaian. Prosiding Penelitian SpeSIA .

Puspasari. (2012). Pengaruh moralitas individu dan pengendalian internal terhadap kecenderungan kecurangan akuntansi : studi eksperimen pada konteks pemerintahan daerah. Tesis Program Pasca Sarjana Universitas Gajah Mada.

Ramamoorti, S. (2008). The Psychology and sociology of fraud: integrating the behavioral sciences component into fraud and forensic accounting curricula. Accounting Education, Vol. 23 No.4.

Santoso, S. (2004). Buku Latihan SPSS Statistik Parametrik. Jakarta: PT Elex Media Komputindo.

Sawyer, L.B. (2006). Sawyer's Internal Auditing. The Practice of Modern Internal Auditing. diterjemahkan oleh Desi Adhariani. Buku 2. Jakarta: Salemba Empat.

Sawyer, L. B., A, D. M., H, S. J. (2005). Internal Auditing Diterjemahkan Oleh: Desi Adhariani, Jilid 1 Edisi 5. Jakarta: Salemba Empat.

Siregar, H., Nurmala, P. (2019). Pengaruh ukuran perusahaan dan penerimaan opini going concern terhadap harga saham. Jurnal Riset Keuangan dan Akuntansi, 4(2), 78-90. https://doi.org/10.25134/jrka.v4i2.1701

Widyawati, D., Nurmala, P. (2019). Pengaruh internal audit, sistem informasi akuntansi, dan sistem pengendalian internal terhadap kinerja karyawan (Studi empiris pada PT BPRS Al Salaam Amal Salman). Portofolio, 16(2), 166-175.

Wulandari, S. \& Nurmala, P. (2018). Pengaruh Ukuran Perusahaan, Intensitas Rapat Komite Audit, dan Ukuran Komite Audit Terhadap Biaya Audit. Jurnal Ilmiah Akuntansi Universitas Pamulang, 7(2), 106-118. http://dx.doi.org/10.32493/jiaup.v7i2.2718 